\title{
"Platinum on the road": Interactions of antitumoral cisplatin with proteins*
}

\author{
Fabio Arnesano and Giovanni Natile \\ Dipartimento Farmaco-Chimico, University of Bari, Bari I-70125, Italy
}

\begin{abstract}
When the antitumor activity of cisplatin was discovered, no one would have thought of the existence of specific proteins able to transport Pt across the cell membrane or to specifically recognize DNA modified by this drug. However, such proteins do exist and, furthermore, are specific for the Pt substrate considered. It follows that proteins are deeply involved in managing the biological activity of cisplatin. It is expected that, after the first 20 years in which most of the efforts were devoted to understanding its mode of interaction with DNA and consequent structural and functional alterations, the role of proteins will be more deeply scavenged. How cisplatin can survive the attack of the many platinophiles present in the extracellular and intracellular media is the issue addressed in this article. Significantly, differences are observed between cisplatin, carboplatin, and oxaliplatin.
\end{abstract}

Keywords: platinum; anticancer drugs; cellular transport; proteins; DNA.

\section{INTRODUCTION}

Cisplatin, cis-diamminedichloridoplatinum(II), has been the first inorganic antitumor drug used in clinics [1] and, after more than 30 years, remains one of the most widely used and successful drugs in cancer therapy $[2,3]$.

Today, cisplatin is routinely used, alone or in combination with other anticancer drugs, for the treatment of lung, ovary, testes, and bladder cancers [4] and shows activity against slow-growing as well as rapidly-growing tumors. However, as with all chemotherapeutic drugs, cisplatin also has drawbacks, including intrinsic or acquired resistance and toxicity. Toxicity and resistance have both a negative influence on the cure rate $[5,6]$.

Some of the severe safety issues have been brought to solution by the introduction of carboplatin, which is equally effective to cisplatin, but with a more acceptable side-effect profile (Fig. 1).

A key development, in more recent years, has been the elucidation of mechanisms of tumor resistance to cisplatin, which include decreased membrane transport of the drug [7,8], increased cytoplasmic detoxification $[9,10]$, increased DNA repair [11-13], and increased tolerance to DNA damage [14-16].

The efforts to circumvent mechanisms of resistance and thereby broaden the clinical utility of this class of agents have resulted in the discovery of oxaliplatin (active in patients with colorectal cancer), satraplatin (the first orally administered Pt drug, which shows promise in patients with prostate cancer), and picoplatin (currently in phase III trials against small-cell lung cancer, prostate cancer, and colorectal cancer). These drugs are shown in Fig. 1.

\footnotetext{
*Paper based on a presentation at the International Symposium on Metallomics 2007 (ISM 2007), 28 November-1 December 2007, Nagoya, Japan. Other presentations are published in this issue, pp. 2565-2750.

‡Corresponding author
} 
<smiles>NP(N)(Cl)(Cl)[GeH2]O</smiles><smiles>CCCC1(C(=O)O[PH2+](N)N)OC1=O</smiles>
carboplatin<smiles>CC(=O)O[N@+](N)(NC1CCCCC1)P(N)(Cl)(Cl)OC(C)=O</smiles>

satraplatin<smiles>N[P](N)(Cl)Cl</smiles>

transplatin<smiles>O=C1O[P]2(N[C@H]3CCCC[C@H]3N2)OC1=O</smiles>

oxaliplatin

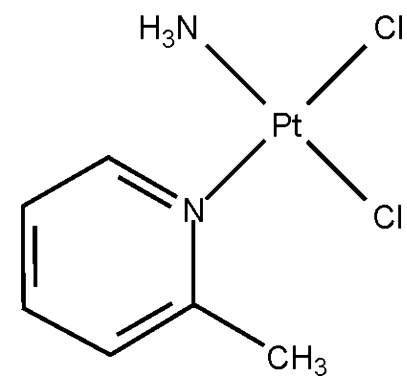

picoplatin

Fig. 1 Structures of Pt complexes, some are currently used in the clinics (cisplatin, carboplatin, oxaliplatin) while others are in the pipeline (satraplatin and picoplatin).

Improved delivery of Pt drugs to tumors is also being studied using liposomal-based $[17,18]$ or co-polymer-based products [19-21], localized administration [22], and also co-administration with specific modulators of major Pt-resistance mechanisms [23-26]. An overview of this field has recently been published [27].

Cisplatin is a simple neutral inorganic compound having square planar geometry and containing a Pt(II) center bonded to two non-labile ammine ligands (carrier ligands) and two labile chlorido ligands (leaving groups) in a cis-configuration. Transplatin has the same composition, but the ligands are in a trans-arrangement. Whereas cisplatin is active against a wide variety of tumors, transplatin is inactive and toxic [28]. The structures of cisplatin and transplatin are also shown in Fig. 1.

Cisplatin, and probably all the Pt drugs just mentioned, have in nuclear DNA their ultimate target. There are several evidences in favor of this thesis. Most importantly, therapeutic effects generally 
correlate with concentrations of $c$ is $-\left\{\mathrm{Pt}\left(\mathrm{NH}_{3}\right)_{2}[\mathrm{~d}(\mathrm{GpG})]\right\}$ metabolite in physiological fluids. This latter represents the final product of degradation of the major cisplatin adduct with DNA, the intrastrand cross-link to adjacent guanines which amounts (together with the analogous cis- $\left\{\mathrm{Pt}\left(\mathrm{NH}_{3}\right)_{2}[\mathrm{~d}(\mathrm{ApG})]\right\}$ adduct) to about $90 \%$ of the total. Note that in this metabolite cisplatin has lost the two chlorido ligands but has kept the two ammines.

How cisplatin can survive the attack of the many platinophiles present in the extracellular and intracellular media is the issue addressed in this article.

\section{DISCUSSION}

\section{Cellular uptake of Pt drugs}

Although passive diffusion through the plasma membrane has been suggested by a number of studies and, at the present, has not been ruled out [29-31]; cellular uptake of Pt drugs may also involve carriers/channels as well as various endocytic routes [32], particularly macropinocytosis [33]. The efflux is generally energy-dependent and biphasic with a rapid early phase and a very long secondary phase $[34,35]$. The kinetics of uptake and efflux of Pt drugs appear to follow a parallel pattern with those of the essential metal $\mathrm{Cu}[34,35]$. This has suggested that the $\mathrm{Cu}$ transporters are also involved in the uptake, intracellular transport, and efflux of Pt drugs.

\section{The role of the $\mathrm{Cu}$ transporter $\mathrm{Ctr1}$}

Deletion of the yeast and mouse $\mathrm{Ctrl}$ gene, coding for a high-affinity $\mathrm{Cu}$ transporter, results in increased cisplatin resistance and decreased cisplatin accumulation [36]. By contrast, human ovarian carcinoma cell lines overexpressing Ctr1 exhibit an increase in cisplatin import [37]. ATP7A and ATP7B, two Cu efflux transporters, are also involved in cisplatin efflux [38-40]. Although these observations suggest that cisplatin uptake and efflux employ $\mathrm{Cu}$ transporters, the mechanism by which these proteins transport the different chemicals $\mathrm{Cu}$ and cisplatin, is yet poorly understood.

Ctr1 has a $N$-terminal extracellular domain carrying methionine-rich motifs. After coordination of $\mathrm{Cu}(\mathrm{I})$, the protein forms a trimer of dimers which features a pore with methionines on the inner surface through which $\mathrm{Cu}$ flows and reaches the intracellular $C$-terminus which is rich in histidines and cysteines [41,42]. From here, $\mathrm{Cu}$ is delivered to chaperones. In all these steps, the $\mathrm{Cu}$ ion is present in a ligand-free ("naked") form, but can Pt use the same pathway and keep the ammines?

In order to address this question, we chose one of the methionine-rich motifs which characterize the extracellular domain of Ctr1 (MSGMSGM), with slight modifications [43] to make it more amenable to water solution investigations (MTGMKGMS, Mets7 hereafter), and performed the reaction with a selection of Pt complexes [44]. The investigation was performed using mainly electrospray ionization mass spectrometry (ESI-MS), NMR, and circular dichroism (CD). From ESI-MS it was clear, right from the beginning, that cisplatin loses one or both ammine ligands and finally coordinates to Mets7 in the naked form. This was confirmed by NMR. The ${ }^{1} \mathrm{H} /{ }^{13} \mathrm{C}$ heteronuclear single-quantum coherence (HSQC) spectrum presented in Fig. 2 reveals a large downfield shift of the $\varepsilon-\mathrm{CH}_{3}$ and $\gamma-\mathrm{CH}_{2}$ protons of methionines which suggests coordination to $\mathrm{Pt}$ of the $\mathrm{S}$ atom. Moreover, the ${ }^{1} \mathrm{H} /{ }^{195} \mathrm{Pt}$ heteronuclear multiple-quantum coherence (HMQC) spectrum confirms the coordination of $\mathrm{S}$ and the loss of the ammines in the case of cisplatin, but not in the case of inactive transplatin. Coordination of $S$ and loss of the ammines also causes a dramatic upfield shift of the Pt resonance in the case of cisplatin, consistent with an (N/O)S3 set of donor atoms [44]. 


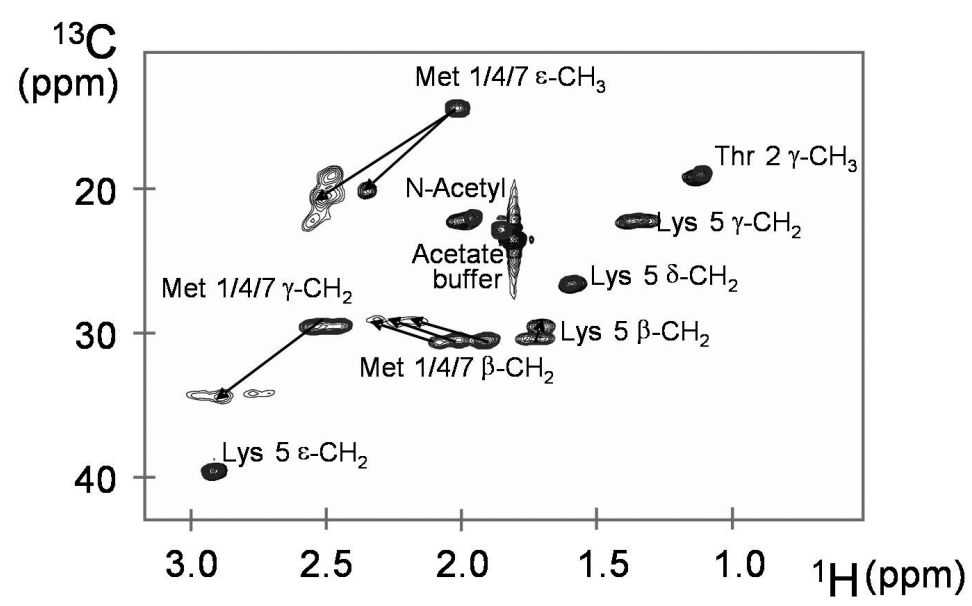

Fig. 2 Overlay of $2 \mathrm{D}{ }^{1} \mathrm{H} /{ }^{13} \mathrm{C}$-edited HSQC spectra of Mets7 and of the 1:1 mixture of Mets7 with cisplatin $24 \mathrm{~h}$ after mixing. Resonance assignments are reported. Spectral changes induced by Pt complexation are indicated with arrows.

The conformation of the peptide, after coordination to Pt, was investigated by $\mathrm{CD}$. The free peptide has a Cotton effect typical of a random coil, after coordination to Pt, a nice spectrum typical of a $\beta$-turn is obtained. The modeled structure of the adduct (present work, Fig. 3) confirms the formation of two $\beta$-turns in the case of cisplatin (three methionines and a chlorido ligand bound to $\mathrm{Pt}$ ).

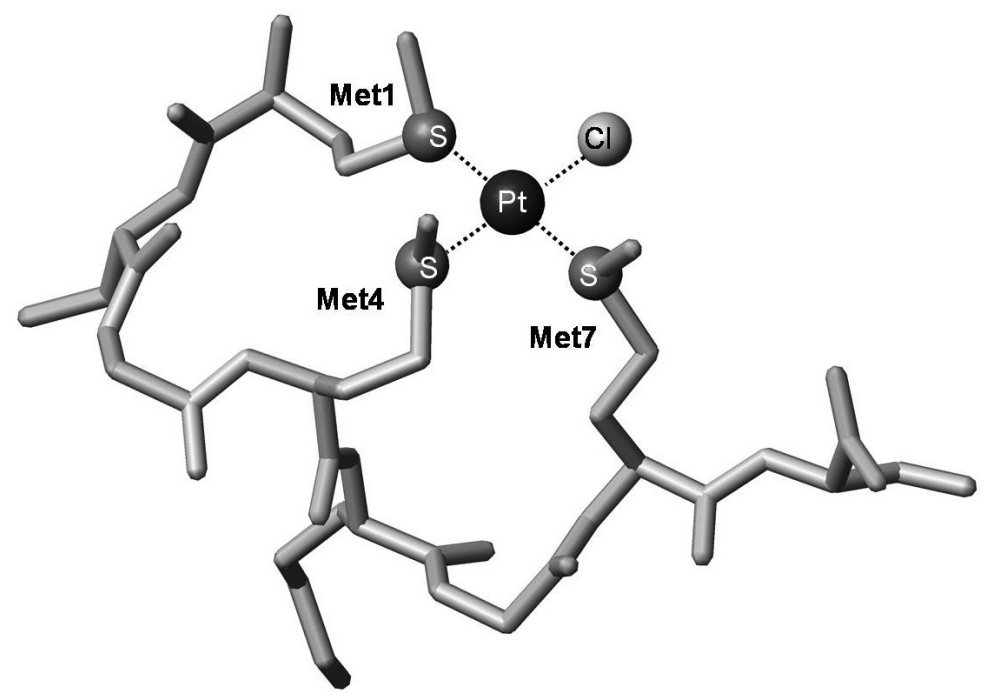

Fig. 3 Structural model of the adduct between cisplatin and Mets7.

In the case of carboplatin (present work), the reaction with Mets7 is much slower and causes the appearance, $24 \mathrm{~h}$ after mixing, of only a weak ESI-MS signal corresponding to the species [Mets7+Pt(1,1-cyclobutanedicarboxylato)] where Pt has lost both ammine ligands and kept the cyclobutanedicarboxylato. The loss of ammine ligands of carboplatin, although quite rare, has been previously reported for the reaction of this drug with the amino acid methionine [45]. The chelating effect of cyclobutanedicarboxylato, but not of the two ammines, may account for this reaction pathway. In 
contrast, in the reaction with oxaliplatin, another Pt drug currently used in chemotherapy, the methionines of Mets 7 are able to efficiently displace the ethanedioato group, leaving the 1,2-cyclohexanediamine ligand bound to Pt. A further Pt(1,2-cyclohexanediamine) moiety can then bind to the peptide, thereby forming a second adduct, as indicated by ESI-MS spectra. The differences in reactivity between the various Pt complexes could be mainly ascribed, among other factors, to the nature of the Pt ligands, to the stability of the chelating rings and to the trans-labilizing effect of the Pt donor atoms.

Importantly, the differences in in vitro reactivity of Pt drugs with methionine-rich motifs may be reflected in a different spectrum of in vivo uptake and anticancer activity.

Going back to cisplatin, there appears to be a perfect parallelism with $\mathrm{Cu}$ : in both cases the metal ion is taken up by methionine-rich motifs in the naked form. This is fine for $\mathrm{Cu}$, which, after translocation through the pore formed at the center of a Ctr1 trimeric complex, reaches the cytoplasmic end of the pore. The cytoplasmic domains may coordinate $\mathrm{Cu}$ and may be involved in its subsequent release to cytoplasmic carriers [46,47]. A few predicted $\mathrm{Cu}$ binding residues, including at least one conserved cysteine residue, are present in these domains [48]. Chaperones can then deliver $\mathrm{Cu}$ to other proteins which use it directly (superoxide dismutase) or bring it to subcellular districts such as the mitochondrion (where it is taken up by cytochrome $c$ oxidase) or to the Golgi (where it is taken up by ceruloplasmin, an iron oxidase) [49].

On the other hand, Pt must keep the amine ligands in order to be active. For antitumor activity, a naked Pt ion would be useless. Therefore, the mechanistic basis of the implication of $\mathrm{Cu}$ metabolic pathways in cisplatin metabolism remains uncertain. Moreover, the observation that a Ctr1 mutant defective in $\mathrm{Cu}$ uptake enhances cisplatin accumulation, whereas a $\mathrm{Cu}$ transport-active $\mathrm{Ctr} 1$ mutant lacking all $\mathrm{N}$-terminal methionine-rich motifs does not accumulate cisplatin, suggests that $\mathrm{Ctr} 1$ employs a different mechanism for $\mathrm{Cu}$ and cisplatin transport. Assuming that the $\mathrm{N}$-terminal methionine-rich motifs play a role in Ctr1-mediated cisplatin uptake, it can be hypothesized that binding of cisplatin to the $\mathrm{N}$-terminus of $\mathrm{Ctr} 1$ is followed by internalization which therefore represents the means for cisplatin uptake. Trafficking of the endocytic vesicles, which inglobate portion of extracellular solution with all chemicals there present, would then deliver these chemicals to subcellular districts and hence to the nucleus. Vesicle trafficking could also serve to protect the drug from attack by cytosolic platinophiles like metallothioneins (MTs) and glutathione (GSH), to mention only two (Fig. 4).

It can be noted that a similar endocytic process has been suggested as an alternative pathway of $\mathrm{Cu}$ uptake. Following $\mathrm{Cu}$ binding to the methionine-rich amino terminal domain, $\mathrm{Ctr} 1$ is internalized through not yet fully understood mechanisms and via the endocytic pathways delivered to lysosomes. Eventually, $\mathrm{Cu}$ enters the cytosol through the function of metal transporters on the lysosomal membrane, such as NRAMP2 [50] and Ctr2 [51].

Further elucidation of the mechanism of action and regulation of Ctr1 would lead to a better understanding of how $\mathrm{Ctr} 1$ can transport the essential metal $\mathrm{Cu}$ and the anticancer drug cisplatin and whether abnormal Ctr1 function and regulation are linked to the development of cisplatin resistance in cancer patients.

We could also show that not only the methionine-rich motifs which characterize the extracellular domain of Ctr1, but also MTs are able to sequester Pt as a naked metal ion. Furthermore, also a protein like cytochrome $c$, which contains on the surface just one isolated methionine residue, reacts with cisplatin displacing one ammine ligand thus inactivating the antitumor drug. 


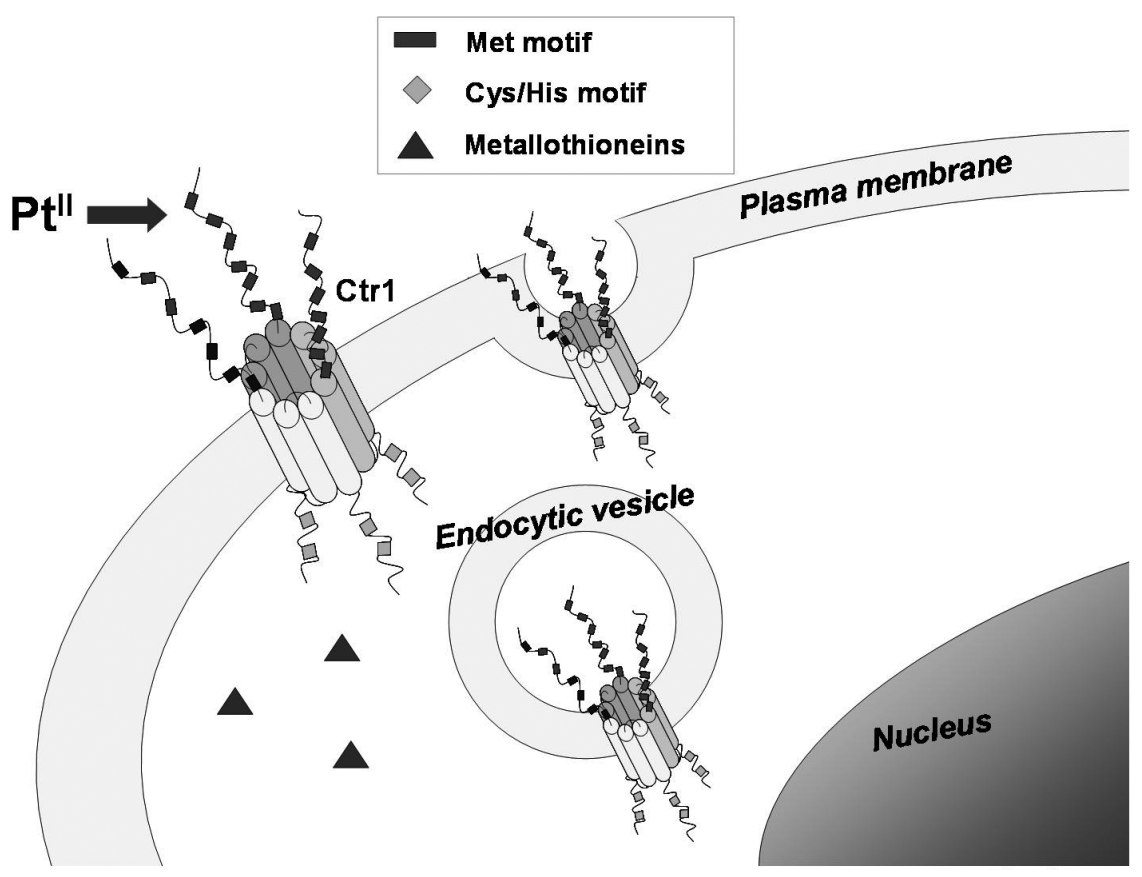

Fig. 4 Model of cisplatin trafficking mediated by $\mathrm{Ctr} 1$. The formation of endocytic vesicles may prevent drug inactivation by MTs and other platinophiles.

\section{The role of metallothioneins}

Although GSH is the most abundant intracellular thiol, its reactivity with Pt compounds is $\sim 50$ times lower than that observed with MT [52]; this makes MT a highly effective intracellular scavenger of $\mathrm{Pt}^{\mathrm{II}}$ drugs which may explain the dramatic resistance increase in cancer cells upon its overexpression [53]. In a recent study, it was shown that human $\mathrm{Zn}_{7}$ MT-2 reacts faster with $\mathrm{Pt}(\mathrm{II})$ compounds having transgeometry (trans-Pt) than with those having cis-geometry (cis-Pt), however, while trans compounds retained their $\mathrm{N}$-donor ligands (thus remaining in a potentially active form), all ligands in cis-Pt compounds were replaced by cysteines thiolates (Fig. 5). Moreover, it was demonstrated that the steric

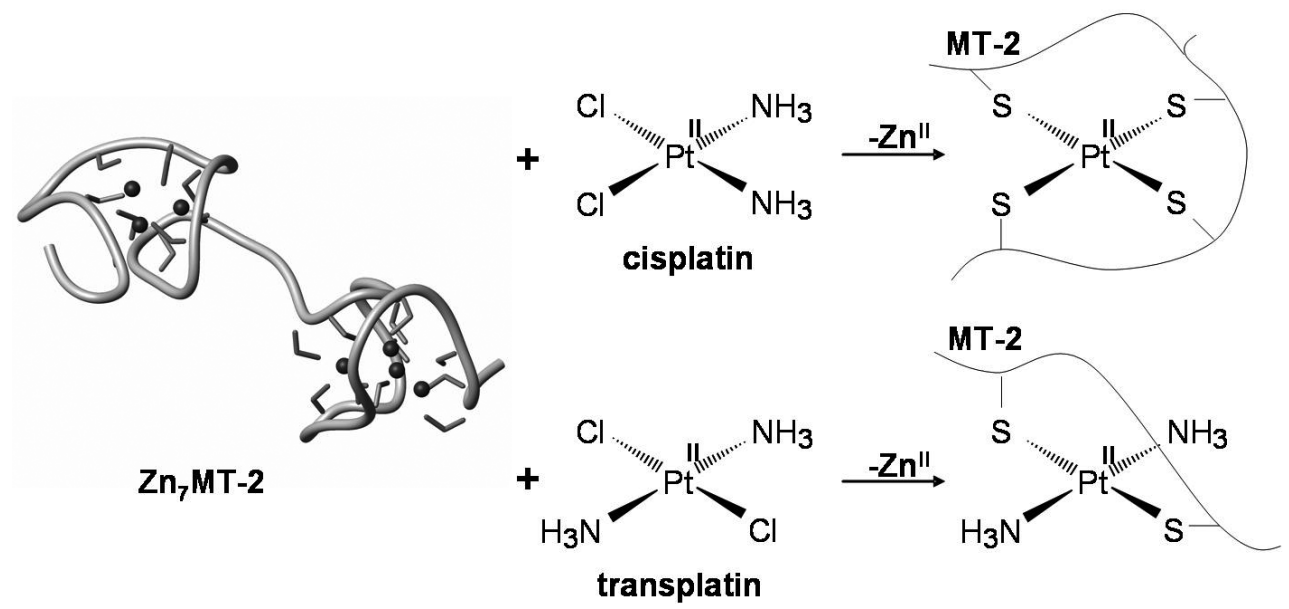

Fig. 5 Reaction of human MT Zn $\mathrm{Z}_{7}$ MT-2 with cisplatin and transplatin. 
hindrance of the Pt ligands represents the major factor influencing the rate of reaction of the Pt drugs with $\mathrm{Zn}_{7}$ MT-2 [54]. The released Zn could also act as efficient activator of MT-2 transcription, leading to even higher expression of this protein [54], and therefore potentiating the resistance of cells. MTs are also good chelators of $\mathrm{Cu}[55,56]$; therefore, once more the metabolisms of $\mathrm{Pt}$ and $\mathrm{Cu}$ result interdependent.

\section{Other proteins}

Several other proteins like serum albumin [57-59], ubiquitin [60-62], myoglobin [61,62], transferrin $[63,64]$, superoxide dismutase [65,66], lysozyme [67], and cytochrome $c$ [68] have been shown to coordinate cisplatin and transplatin mainly through methionine, cysteine, or histidine, and in some instances also through a threonine residue. A single methionine appears to be the preferential binding site in the case of cytochrome $c$ (Met 65), which therefore appears to be a quite simple model for this type of investigation [69]. Once more, a striking difference has been observed between cis- $\mathrm{Pt}$ and trans-Pt complexes. While trans-Pt compounds retain both $\mathrm{N}$-donor ligands, cis-Pt species lose one "nonlabile" ligand, thus resulting inactivated (Fig. 6).

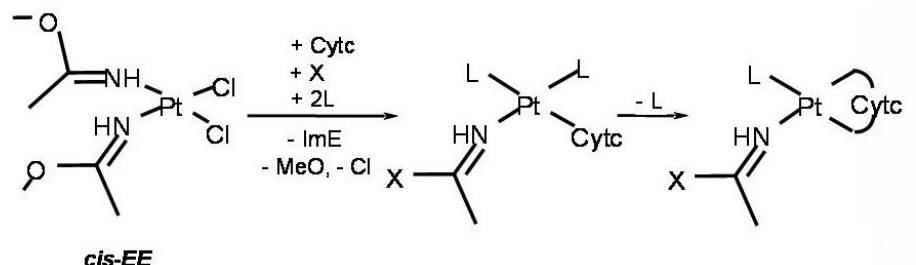

$\mathrm{L}=\mathrm{H}_{2} \mathrm{O}, \mathrm{NH}_{3} ; \mathrm{X}=\mathrm{OH}, \mathrm{NH}_{2} ; \mathrm{ImE}=$ iminoether
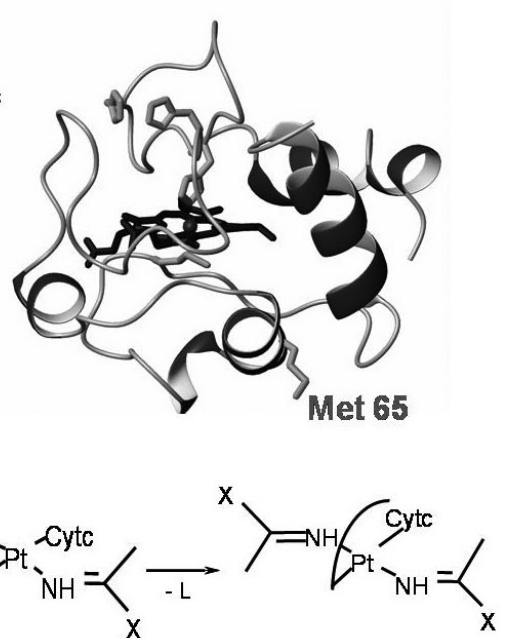

Fig. 6 Reaction of horse hearth cytochrome $c$ (shown in the inset) with cis-EE and trans-EE Pt iminoether complexes in ammonium carbonate buffer.

\section{CONCLUSIONS}

The biological and pharmacological implications of the protein-metallodrug interactions are just being unraveled and call for a wider and deeper investigation which, ultimately, can clarify the full role proteins play in transport, accumulation and pharmacological action of Pt drugs.

The known high affinity of Pt compounds for S atoms and the great abundance of S-containing biomolecules in the cytosol and in the cell nucleus have raised the question whether Pt-S interactions could serve as a drug reservoir affording an additional pathway toward platination of DNA [70,71]. In the light of latter results, this possibility appears to be quite unlikely.

The processing of metallic compounds (including exogenous metallodrugs) by the cell machinery should also be within the scope of metallomics. 


\section{EXPERIMENTAL SECTION}

\section{Modeling}

The structural models of the adducts of the octapeptide Mets7 (MTGMKGMS) with cisplatin was obtained with the minimization protocol of the program PSEUDODYANA [72]. Structure calculations were performed by linking the Pt ion to the appropriate ligand group (i.e., M1, M4, M7, and $\mathrm{Cl}^{-}$) and constraining the metal-ligand bond length in the range 2.2-2.4 $\AA$ for S donor methionine and for chlorido ligands, according to X-ray absorption spectroscopy (XAS) data (unpublished results). The Pt ion and the $\mathrm{Cl}^{-}$ligand were introduced in the PSEUDODYANA library as nonstandard residues. The Pt geometry was imposed to be square planar. Model analysis and display were performed with the program MOLMOL [73].

\section{Electrospray mass spectrometry}

The reaction of the octapeptide Mets7 with carboplatin and oxaliplatin was followed by ESI-MS. ESI-MS was performed with an electrospray interface and an ion trap mass spectrometer (1100 Series LC/MSD Trap system Agilent, Palo Alto, CA). Aliquots of reaction mixtures of Mets7 with the two Pt complexes were removed at different times after mixing, diluted to a final concentration of $20 \mu \mathrm{M}$ and infused via a KD Scientific syringe pump at a rate of $10 \mu \mathrm{L} / \mathrm{min}$. Ammonium acetate $5 \mathrm{mM}$ was also added in order to obtain a good volatilization in mild acidic conditions ( $\mathrm{pH} 6$ ). Ionization was achieved in the positive ion mode by application of $+4 \mathrm{kV}$ at the entrance of the capillary; the pressure of the nebulizer gas was 15 psi. The drying gas was heated to $350{ }^{\circ} \mathrm{C}$ at a flow of $5 \mathrm{~L} / \mathrm{min}$. Full-scan mass spectra were recorded in the mass/charge $(\mathrm{m} / \mathrm{z})$ range of 50-1500. Isotopic distributions were calculated with the program Molecular Weight Calculator (<http://ncrr.pnl.gov/software/>).

\section{Materials}

The peptide Mets7, acetylated at its $N$-terminus, was purchased from GenScript Corp. The purity was validated to be greater than $98 \%$ by analytical high-performance liquid chromatography (HPLC), and the mass was confirmed by ESI-MS. Calcd for $\mathrm{C}_{34} \mathrm{H}_{61} \mathrm{~N}_{9} \mathrm{O}_{12} \mathrm{~S}_{3}$ : 883.36; found: [Mets7+H+ $\mathrm{H}^{+}$] 883.90. The complexes carboplatin and oxaliplatin were purchased from Sigma-Aldrich Corp. Stock solutions at $\mathrm{mM}$ concentration were prepared by dissolving the lyophilized peptide and the Pt complexes in nanopure water. All reaction mixtures were obtained with equimolar amounts of Mets7 and Pt complex.

\section{ACKNOWLEDGMENTS}

The authors thank the University of Bari, the Italian Ministero dell'Università e della Ricerca (PRIN 2005032730), the Consorzio Interuniversitario di Ricerca in Chimica dei Metalli nei Sistemi Biologici (CIRCMSB), and EC (Cost Action D39) for support. We gratefully acknowledge Dr. Francesco Cannito of CIRCMSB for assistance in manuscript preparation.

\section{REFERENCES}

1. J. Drobnik. Cancer Chemother. Pharmacol. 10, 145 (1983).

2. P. Pil, S. J. Lippard. In Encyclopedia of Cancer, J. R. Bertino (Ed.), pp. 392-410, Academic Press, San Diego (1997).

3. U. Bierbach, Y. Qu, T. W. Hambley, J. Peroutka, H. L. Nguyen, M. Doedee, N. Farrell. Inorg. Chem. 38, 3535 (1999).

4. P. Di Blasi, A. Bernareggi, G. Beggiolin, L. Piazzoni, E. Menta, M. L. Formento. Anticancer Res. 18, 3113 (1998). 
5. K. J. Scanlon, M. Kashani-Sabet, H. Miyachi, L. C. Sowers, J. Rossi. Anticancer Res. 9, 1301 (1989).

6. R. P. Perez, T. C. Hamilton, R. F. Ozols, R. C. Young. Cancer 71, 1571 (1993).

7. R. Safaei, A. K. Holzer, K. Katano, G. Samimi, S. B. Howell. J. Inorg. Biochem. 98, 1607 (2004).

8. G. Samimi, R. Safaei, K. Katano, A. K. Holzer, M. Rochdi, M. Tomioka, M. Goodman, S. B. Howell. Clin. Cancer Res. 10, 4661 (2004).

9. J. Holford, P. J. Beale, F. E. Boxall, S. Y. Sharp, L. R. Kelland. Eur. J. Cancer 36, 1984 (2000).

10. P. Yang, J. O. Ebbert, Z. Sun, R. M. Weinshilboum. J. Clin. Oncol. 24, 1761 (2006).

11. K. V. Ferry, T. C. Hamilton, S. W. Johnson. Biochem. Pharmacol. 60, 1305 (2000).

12. I. Y. Chang, M. H. Kim, H. B. Kim, D. Y. Lee, S. H. Kim, H. Y. Kim, H. J. You. Biochem. Biophys. Res. Commun. 327, 225 (2005).

13. E. Reed. Clin. Cancer Res. 11, 6100 (2005).

14. D. Fink, S. Nebel, S. Aebi, H. Zheng, B. Cenni, A. Nehme, R. D. Christen, S. B. Howell. Cancer Res. 56, 4881 (1996).

15. E. Bassett, A. Vaisman, K. A. Tropea, C. M. McCall, C. Masutani, F. Hanaoka, S. G. Chaney. DNA Repair (Amst) 1, 1003 (2002).

16. M. R. Albertella, C. M. Green, A. R. Lehmann, M. J. O'Connor. Cancer Res. 65, 9799 (2005).

17. S. C. White, P. Lorigan, G. P. Margison, J. M. Margison, F. Martin, N. Thatcher, H. Anderson, M. Ranson. Br. J. Cancer 95, 822 (2006).

18. T. Dragovich, D. Mendelson, S. Kurtin, K. Richardson, H. D. Von, A. Hoos. Cancer Chemother. Pharmacol. 58, 759 (2006).

19. J. M. Rademaker-Lakhai, C. Terret, S. B. Howell, C. M. Baud, R. F. De Boer, D. Pluim, J. H. Beijnen, J. H. Schellens, J. P. Droz. Clin. Cancer Res. 10, 3386 (2004).

20. J. R. Rice, J. L. Gerberich, D. P. Nowotnik, S. B. Howell. Clin. Cancer Res. 12, 2248 (2006).

21. M. Campone, J. M. Rademaker-Lakhai, J. Bennouna, S. B. Howell, D. P. Nowotnik, J. H. Beijnen, J. H. Schellens. Cancer Chemother. Pharmacol. 60, 523 (2007).

22. D. K. Armstrong, B. Bundy, L. Wenzel, H. Q. Huang, R. Baergen, S. Lele, L. J. Copeland, J. L. Walker, R. A. Burger. N. Engl. J. Med. 354, 34 (2006).

23. A. S. Morgan, P. E. Sanderson, R. F. Borch, K. D. Tew, Y. Niitsu, T. Takayama, D. D. Von Hoff, E. Izbicka, G. Mangold, C. Paul, U. Broberg, B. Mannervik, W. D. Henner, L. M. Kauvar. Cancer Res. 58, 2568 (1998).

24. D. M. Townsend, H. Shen, A. L. Staros, L. Gate, K. D. Tew. Mol. Cancer Ther. 1, 1089 (2002).

25. J. J. Kavanagh, D. M. Gershenson, H. Choi, L. Lewis, K. Patel, G. L. Brown, A. Garcia, D. R. Spriggs. Int. J. Gynecol. Cancer 15, 593 (2005).

26. J. A. Plumb, G. Strathdee, J. Sludden, S. B. Kaye, R. Brown. Cancer Res. 60, 6039 (2000).

27. L. Kelland. Nat. Rev. Cancer 7, 573 (2007).

28. B. Lippert. In Metal Ions in Biological Systems, A. Sigel, H. Sigel (Eds.), pp. 105-141, Marcel Dekker, New York (1996).

29. R. A. Hromas, J. A. North, C. P. Burns. Cancer Lett. 36, 197 (1987).

30. S. C. Mann, P. A. Andrews, S. B. Howell. Cancer Chemother. Pharmacol. 25, 236 (1990).

31. S. P. Binks, M. Dobrota. Biochem. Pharmacol. 40, 1329 (1990).

32. R. Safaei, K. Katano, G. Samimi, A. K. Holzer, W. Naerdemann, S. B. Howell. Proc. Am. Assoc. Cancer Res. 45, 120 (2004).

33. A. K. Holzer, S. B. Howell. Cancer Res. 66, 10944 (2006).

34. K. Katano, A. Kondo, R. Safaei, A. Holzer, G. Samimi, M. Mishima, Y. M. Kuo, M. Rochdi, S. B. Howell. Cancer Res. 62, 6559 (2002).

35. R. Safaei, K. Katano, G. Samimi, W. Naerdemann, J. L. Stevenson, M. Rochdi, S. B. Howell. Cancer Chemother. Pharmacol. 53, 239 (2004).

36. S. Ishida, J. Lee, D. J. Thiele, I. Herskowitz. Proc. Natl. Acad. Sci. USA 99, 14298 (2002). 
37. A. K. Holzer, G. Samimi, K. Katano, W. Naerdemann, X. Lin, R. Safaei, S. B. Howell. Mol. Pharmacol. 66, 817 (2004).

38. R. Safaei, S. B. Howell. Crit. Rev. Oncol. Hematol. 53, 13 (2005).

39. M. Komatsu, T. Sumizawa, M. Mutoh, Z. S. Chen, K. Terada, T. Furukawa, X. L. Yang, H. Gao, N. Miura, T. Sugiyama, S. Akiyama. Cancer Res. 60, 1312 (2000).

40. G. Samimi, K. Katano, A. K. Holzer, R. Safaei, S. B. Howell. Mol. Pharmacol. 66, 25 (2004).

41. S. G. Aller, V. M. Unger. Proc. Natl. Acad. Sci. USA 103, 3627 (2006).

42. S. Lee, S. B. Howell, S. J. Opella. Biochim. Biophys. Acta 1768, 3127 (2007).

43. J. Jiang, I. A. Nadas, M. A. Kim, K. J. Franz. Inorg. Chem. 44, 9787 (2005).

44. F. Arnesano, S. Scintilla, G. Natile. Angew. Chem., Int. Ed. 46, 9062 (2007).

45. Q. Liu, J. Lin, P. Jiang, J. Zhang, L. Zhu, Z. Guo. Eur. J. Inorg. Chem. 2002, 2170 (2002).

46. Z. Xiao, A. G. Wedd. Chem. Commun. 6, 588 (2002).

47. Z. Xiao, F. Loughlin, G. N. George, G. J. Howlett, A. G. Wedd. J. Am. Chem. Soc. 126, 3081 (2004).

48. D. Sinani, D. J. Adle, H. Kim, J. Lee. J. Biol. Chem. 282, 26775 (2007).

49. F. Arnesano, L. Banci. In Handbook of Metalloproteins, A. Messerschmidt (Ed.), John Wiley, New York (2007).

50. M. Arredondo, P. Munoz, C. V. Mura, M. T. Nunez. Am. J. Physiol. Cell Physiol. 284, C1525 (2003).

51. E. M. Rees, J. Lee, D. J. Thiele. J. Biol. Chem. 279, 54221 (2004).

52. D. Hagrman, J. Goodisman, J. C. Dabrowiak, A. K. Souid. Drug Metab. Dispos. 31, 916 (2003).

53. S. L. Kelley, A. Basu, B. A. Teicher, M. P. Hacker, D. H. Hamer, J. S. Lazo. Science 241, 1813 (1988).

54. M. Knipp, A. V. Karotki, S. Chesnov, G. Natile, P. J. Sadler, V. Brabec, M. Vasak. J. Med. Chem. 50, 4075 (2007).

55. P. G. Farnworth, B. L. Hillcoat, I. A. Roos. Chem. Biol. Interact. 69, 319 (1989).

56. A. J. Zelazowski, J. S. Garvey, J. D. Hoeschele. Arch. Biochem. Biophys. 229, 246 (1984).

57. P. J. Sadler, A. Tucker, J. H. Viles. Eur. J. Biochem. 220, 193 (1994).

58. A. I. Ivanov, J. Christodoulou, J. A. Parkinson, K. J. Barnham, A. Tucker, J. Woodrow, P. J. Sadler. J. Biol. Chem. 273, 14721 (1998).

59. L. Trynda-Lemiesz, H. Kozlowski, B. K. Keppler. J. Inorg. Biochem. 77, 141 (1999).

60. T. Peleg-Shulman, D. Gibson. J. Am. Chem. Soc. 123, 3171 (2001).

61. T. Peleg-Shulman, Y. Najajreh, D. Gibson. J. Inorg. Biochem. 91, 306 (2002).

62. Y. Najajreh, T. Peleg-Shulman, O. Moshel, N. Farrell, D. Gibson. J. Biol. Inorg. Chem. 8, 167 (2003).

63. M. C. Cox, K. J. Barnham, T. A. Frenkiel, J. D. Hoeschele, A. B. Mason, Q. Y. He, R. C. Woodworth, P. J. Sadler. J. Biol. Inorg. Chem. 4, 621 (1999).

64. C. S. Allardyce, P. J. Dyson, J. Coffey, N. Johnson. Rapid Commun. Mass Spectrom. 16, 933 (2002).

65. S. K. Weidt, C. L. Mackay, P. R. Langridge-Smith, P. J. Sadler. Chem. Commun. 1719 (2007).

66. V. Calderone, A. Casini, S. Mangani, L. Messori, P. L. Orioli. Angew. Chem., Int. Ed. 45, 1267 (2006).

67. A. Casini, G. Mastrobuoni, C. Temperini, C. Gabbiani, S. Francese, G. Moneti, C. T. Supuran, A. Scozzafava, L. Messori. Chem. Commun. 156 (2007).

68. A. Casini, C. Gabbiani, G. Mastrobuoni, L. Messori, G. Moneti, G. Pieraccini. ChemMedChem 1, 413 (2006).

69. A. Casini, C. Gabbiani, G. Mastrobuoni, R. Z. Pellicani, F. P. Intini, F. Arnesano, G. Natile, G. Moneti, S. Francese, L. Messori. Biochemistry 46, 12220 (2007).

70. J. Reedijk. Chem. Rev. 99, 2499 (1999).

71. B. Wu, P. Droge, C. A. Davey. Nat. Chem. Biol. 4, 110 (2008). 
72. L. Banci, I. Bertini, M. A. Cremonini, G. Gori Savellini, C. Luchinat, K. Wüthrich, P. Güntert. J. Biomol. NMR 12, 553 (1998).

73. R. Koradi, M. Billeter, K. Wüthrich. J. Mol. Graphics 14, 51 (1996). 